\title{
VALLE-INCLÁN, DRAMATURGO: LA DIFICULTAD DE SER PRECURSOR
}

\author{
Víctor Valembois \\ Universidad de Costa Rica
}

\section{Valle-Inclán, el hombre y su obra, difíciles de encasillar}

Modernidad, postmodernidad, modernismo: al caso del escritor español don Ramón María del Valle-Inclán (1866-1936) le cabrían todas o ninguna de estas taxonomías porque su biografía y su obra resultan relativamente inseparables. El hombre y su creación se muestran bastante escurridizos en cuanto a la aplicación de etiquetas. Frente a este obstáculo insoslayable, Francisco Ruiz Ramón en su ya clásica Historia del Teatro Español ${ }^{1}$ prefirió encasillar al caballero de las "luengas barbas" (junto con Unamuno, Azorín y otros de la llamada "generación del 98" -jotra taxonomía!) dentro de un grupo de "innovadores y disidentes".

Que Valle-Inclán era innovador al mismo tiempo que disidente, lo sabía él mismo y lo practicaba a conciencia, en su estilo vital y en su creación artística, asumiendo las consecuencias. Sin que sea mi intención caer en lo que demasiadado se ha caido, a saber, confundir el hombre de las anecdotas famosas y de la frase lapidaria con su creación, (error al que el mismo Valle en cierto sentido contribuyó falseando su propia biografía), viene de perlas citar aquí su propia aseveración respecto del resultado de esta postura iconoclasta: "Me ha fallado la época. ¡Qué le voy a hacer! Es un fallimiento demasiado grande para que pueda arreglarlo un hombre solo." Este desajuste en el tiempo, este exilio en su propia tierra es precisamente lo que caracteriza al precursor. Mi propósito aquí será entonces analizar en qué sentido y por qué a Don Ramón, dramaturgo, "le falló la época" ... y por qué se puede afirmar que, casi con un desfase de medio siglo, en España, en Europa y en el continente americano, entre otros Costa Rica, a partir de los años sesenta, a Valle le ha llegado la hora... ${ }^{2}$

Estoy de acuerdo por de pronto con la aseveración de Buero Vallejo 3 para el que parece absurdo estarse interrogando todavía si en realidad Valle-Inclán fue o no dramaturgo. El autor de En la ardiente oscuridad ${ }^{4}$, se hacía la pregunta más bien en el sentido interior, que si las obras dramáticas de Valle, en realidad, son o no son teatro, por su nexo novelesco y la cantidad de acotaciones. Aquí parto de una observación mucho más extensa y directa, cual es que varias de sus obras "teatrales" lo son primero porque generalmente fueron llevadas a escena ${ }^{5}$, aunque sea para ser estrenos de "una noche y gracias", como decía su autor. En su tiempo nadie ponía en duda la condición de dramaturgo de Valle-Inclán, de modo que su problema de desconocimiento no resulta comparable con el de otros que no gozaron nunca del privilegio de las tablas y tuvieron que refugiarse detrás de la dudosa categoría del "teatro leído", hasta ser descubiertos, 
después por algún director. En el caso de autor de Luces de Bohemia, no asistimos entonces a un caso de desconocimiento por parte del público, sino al tipo de "desface" que caracteriza al autor de vanguardia.

Son múltiples las causas para esta falta de acoplamiento en el tiempo. Las hay de orden interno a las obras, como el tipo externo, debidas a la misma personalidad de su autor. Además, ambos, la producción y el productor, no se acomodan dentro de su contexto cultural y político, su "circunstancia", según la clásica expresión de Ortega y Gasset. Metodológicamente voy a ahondar en cuatro factores, agrupados en dos tipos: hay tres condicionantes más bien de tipo estético, inherentes a una conceptualización del arte de Talía; hay en seguida un elemento netamente exterior, por no encajar Valle-Inclán dentro del ordenamiento político de la época en que habría podido ser un dramaturgo aceptado y celebrado.

\section{Enfoque metodológico: de la práctica ... a la teoría}

Para el análisis de rigor todo se complica, al comprobar que Don Ramón casi no dejó reflexión teórica plasmando su propia visión artística. La excepción consiste en un texto corto, publicado por Martínez Sierra ${ }^{6}$ en el diario $A B C$, a los dos años de la muerte del gallego. Lo sorprendente en el caso de Valle-Inclán es, nuevamente, que uno, como investigador, todavía a estas alturas de fines del siglo veinte, choca con una falta de sistematización respecto de los diversos aportes teóricos que ha dado Valle-Inclán a lo largo de su vida. Sin embargo, viéndolo de un poco más cerca, no deben de ser pocos los elementos rescatables de esta estética. Aparte de que las mismas anecdotas -ya en espejo deformante- permiten deducir un código, habría información tanto en publicaciones como en conferencias, ya sea en el viejo continente, aunque sea a nivel de charlas de café, como en el Nuevo Mundo: en cuanto a este último, por ejemplo, no conozco un rastreo sistemático de lo que Don Ramón, como Director artístico de la Compañía teatral Guerrero-Mendoza, dijo y escribió respecto de su peculiar concepto del arte, estando, entre otros en México y en Argentina, alrededor de 1910. De llevarse a cabo esta ingente labor de búsqueda, sorprendentemente descubriríamos un Valle-Inclán teórico, si no cronológicamente contemporáneo, por lo menos mentalmente afin con Meyerhold y Stanislawski.

Por lo anterior hay que deducir, destilar la visión teórica de Valle de su práctica, cosa que no deja de conllevar a priori dificultades: ¿hasta qué punto es legítimo, por ejemplo, asimilar al personaje Max Estrella, visiblemente bajo el efecto etílico además, con la persona de Valle-Inclán? ¿La situación "dramática" de la obra nos permite el salto mortal hacia la vida real, por muy "dramática" que sea, esta también? ¿No asistiremos automáticamente a una confusión metodológica y por ende terminológica en el acercamiento de los dos planos? Al respecto, quizá la sistemática costumbre de Valle-Inclán de ignorar la clásica dicotomía vida - obra, pareciera autorizarnos para explotar esta peligrosa interferencia...

\section{3. ¿Qué es el teatro, para Valle-Inclán ?}

Salta a la vista que la dificultad para situar al autor como novelista, como dramaturgo 0 como director de cine se debe precisamente a que él, con un manejo iconoclasta al respecto, quiere romper con una visión encasilladora. Como Azorín, compañero de ruta en lo que los cri- 
ticos han dado en llamar la "Generación del 98", Valle-Inclán estuvo siempre fascinado por las posibilidades del séptimo arte. Error sería sin embargo ver en el un precursor del cine o, en otros términos, que llevando a sus obras a la pantalla se solucionaría todo el problema. El coqueteo con lo fílmico, en Valle pareciera entonces obedecer más a la necesidad de salir de la visión encarcelada en que habían metido el arte de Talía los naturalistas y teatristas "sicológicos" en boga en su época, del tipo Echegaray y Benavente. De ellos dijo Valle: "Con los recursos de presencia que el teatro tiene nos echan a la cara trozos de la realidad. El arte no existe sino cuando ha superado sus modelos vivos mediante una elaboración ideal". Esta última, desde luego no ha de ser confundida con una elaboración idealista, como sí lo pregonaban y aplicaban sus oponentes.

Que Valle-Inclán era así un adelantado en cuanto a "idea del teatro", no quita, sin embargo, que al mismo tiempo se aferrara, en determinados aspectos, a una visión muy conservadora del arte teatral. Resulta fácil detectar en cualquiera de sus obras la clásica sobrevaloración del dramaturgo, en detrimento de los otros componentes en la codificación global del signo teatral, con el director, el actor, el escenógrafo, etc. En una reacción pendular después se irían exagerando estos, en detrimento del autor dramático. Don Ramón guardaba para sí toda la tarea creativa con una visión de señor patriarcal y omnipotente que construye con el verbo para que los demás, subordinados, ejecuten sus instrucciones. De ahí sus acotaciones excesivas, novelescas, con la visión glotocentrista de que, planteadas las cosas sobre el papel allá los demás para la ejecución ${ }^{8}$. Esta misma visión jerárquica del dramaturgo y de su creación contribuyó ciertamente también a su reconocimiento tardío.

La idea del teatro que prevalece en Valle-Inclán tiene así mucho ya de lo que Alejandro Casona después identificaría, tan plásticamente, como "la gran mentira desnuda". Al rastrearse acerca de los origenes de esta conceptualización teatral esencialmente anti-realista en Valle-Inclán pareciera que ha de evitarse caer en el extremo de verlo todo como una evolución "desde el huevo inicial", donde ya estaba todo ${ }^{9}$. Me inclino sin embargo a pensar que la conceptualización del esperpento parte de una generalización de lo deformante: el mismo modernismo de los cisnes y los mirtos, las rozas y las liras, iba más allá de los "trozos de realidad". En este sentido, Valle-Inclán seguirá "modernista" hasta el final: su propuesta es de hacerlo sistemáticamente ${ }^{10}$. Solo que observamos en él una doble modificación. Por una parte, para crear, el artista va recurriendo cada vez más al teatro, aunque sea en su forma preliminar de literatura dramática, y ya no tanto a la poesía o a la novela. Por otra parte asistimos también a una revolución copernicana en la estética de la deformación, porque se supera el reduccionismo burgués con su asimilación pauperizante de lo estético y lo bello, como si aparte de las Bellas Artes, Valle-Inclán no lograra magistralmente la pintura de lo feo" ${ }^{11}$, lo cruel, lo degradado mucho antes de que Artaud ${ }^{12}$ lo pidiera a gritos, ... solo que teóricamente y por lo menos una década después del gallego.

Es interesante estudiar Los cuernos de Don Friolera para precisar la idea de teatro que prevalece en Valle-Inclán. Menos estudiada y citada a diestra y siniestra como ocurre especialmente con las declaraciones estéticas de Max Estrella en Luces de Bohemia, la obra Los cuernos... ofrece, por una parte una sorprendente riqueza semiológica ${ }^{13}$, pero además, ésta perfila mejor que otras, creo yo, que en Valle-Inclán la crueldad inherente a la visión esperpéntica no queda exenta de humanismo. Recordemos que la obra está estructurada en forma de tríptico. Se narra tres veces la misma historia, la primera y la tercera vez en forma sustancialmente más 
reducida que en la versión central. Lo unificador está por una parte en lo idéntico de la temática y por otra parte en que se trata de tres matices dentro de una misma esperpentización.

$\mathrm{Al}$ afirmar eso, discrepo totalmente del citado Ruiz Ramón, según el cual las partes de la trilogía serían cada vez aplicación de uno de los puntos de vista ("de rodillas, en pie, en el aire") señalados. Tiene razón este historiador del teatro español al señalar que la primera parte, la del bululú, corresponde en sí a la perspectiva "en el aire" y que la tercera, la del romance de ciegos, obedece formalmente a la versión "de rodillas"; pero argumenta Ruiz que "la segunda versión, mucho más amplia y matizada que las dos anteriores, constituye el cuerpo central de la pieza y es la que corresponde a la visión esperpéntica"14. El problema es que para completar la triple aproximación posible a la realidad, esa parte debería entonces corresponder a la visión "en pie" que definitivamente no puede ser esperpéntica, como lo señala el mismo Valle-Inclán en su propia teorización ${ }^{15}$. En realidad, una cosa es ver las partes de la obra en sí, y otra es apreciarla en conjunto: ni el bululú ni el romance de ciegos están siendo respetados dentro de los cánones clásicos de los géneros, sino que a su vez están sometidos, como toda la obra, en forma "sistemática", al "espejo cóncavo". Es cuestión de aplicar consecuentemente a Los cuernos... las reglas postuladas por Max Estrella en Luces de Bohemia.

Así las cosas, Valle-Inclán no tiene más remedio que recurrir a las formas literarias existentes, superando, desde luego la dicotomía clásica de la comedia y la tragedia, que prevaleció demasiado tiempo anquilozando el teatro al norte de los Pirineos, que no tanto en la España desde Lope. Pero al mismo tiempo, al igual por cierto que en Michel de Ghelderode, hay una utilización de llamados "subgéneros" que la burguesía no aceptaría como arte, como la farsa popular, el melodrama, lo circense, etc. En ambos dramaturgos, nuevamente con algo más de carácter precursor en Valle, se trata de una búsqueda formal, siempre con el propósito de postular una idea del teatro que rompa con el esquema anémico que prevalecía. En tiempos de Valle, felizmente ya no tanto en el caso de Ghelderode, la condena del artista resultó absoluta en nombre de la taxonomía, porque de Aristóteles hasta el naturalismo burgués se había valorado la obra en función de los géneros, en vez de proceder al revés. Los dos autores propugnan en este sentido no la creación de un teatro más, sino la invención de un nuevo teatro, o en todo caso, la oxigenación por la vida, del teatro heredado pero anémico. En el caso de Valle, hay un poderoso antecedente de otra creación artística difícilmente ubicable por género, pero no por eso menos poderosa, por su fuerza interna, me refiero a La Celestina.

\section{4. ¿Para qué el teatro, según Valle-Inclán?}

Cierta línea crítica, secundada por una enseñanza simplificadora generalizada ${ }^{16}$, opone tajantemente un Valle-Inclán frente a otro distinto y hasta opuesto, uno como exponente del modernismo y otro, que para el caso vamos a identificar como el esperpéntico. Esta conceptualización parte de un esquema demasiado enraizado según el cual en el modernismo, aparte de artífice y belleza estereotipada, se reflejara basicamente evasión. Flaco favor le haríamos a esta corriente artística en general y a dos de sus exponentes en uno y otro lado del Atlántico, si no vieramos en uno y otro también huellas de todo lo contrario de escapismo social, desde la Oda a Roosevelt de uno hasta la necesidad constante en Valle de reflexionar en cuanto a su entorno y de asumir invariablemente una postura al respecto. Indudablemente que esta tendencia se vio 
reforzada en la actividad teatral de Don Ramón. Sin caer ni en el didactismo ni en el teatro político, en el sentido de partidista, siempre detectamos en él una preocupación por la comunidad, el conjunto de la "polis" griega. La reflexión acerca de la función del teatro, en Valle conlleva entonces forzasamente también observaciones acerca de su concepto del público teatral y en última instancia de percepción de lo popular.

Resulta nuevamene revelador, al respecto, ver un mismo tipo de búsqueda en Ghelderode y en Valle-Inclán, por la recurrencia a lugares de su propia biografía, de su propia infancia, Flandes y Galicia, pero en términos no de reconstrucción arqueológica sino de elaboración mítica, en ambos con una distancia física, espacial, de por medio (estos lugares vistos desde la capital, Bruselas o Madrid) y con una distancia temporal (la evocación de un pasado etéreo, que mal esconde la visión crítica de la actualidad). La actualidad de los dos autores se transluce a partir de una paralela reacción contra un mismo agotamieno cultural europeo, constatado en dos latitudes distintas y distantes ${ }^{17}$. Como vimos más arriba, el paralelismo entre los dos autores implica también una manera de hacer teatro que trasciende el mero enfoque formal, genérico, para constituirse en una auténtica visión dramática del arte y de la realidad ${ }^{18}$.

Ahora bien, este teatro de interrogación y de búsqueda, que no de afirmación y adormecimiento, choca completamente con el modelo vigente en la época de Valle. La síntesis de José Ruibal es elocuente al respecto: "Benavente escribía para su público; Valle-Inclán, en contra de él". La misma escogencia del nombre de su estética va en el mismo sentido, no precisamente de halagar, sino de asustar, provocar el horror ${ }^{19}$. Y el paralelismo a nivel europeo sigue: hay una tercera relación entre Valle-Inclán y Ghelderode, al comprobar que ellos tardaron en ser aceptados por enfrentarse en su conceptualización y funcionalidad del teatro con los sectores oficiales. ¿Será casualidad que no se diera sendos premios Nobel a ellos sino a sus oponentes ${ }^{20}$ artísticos, a saber Benavente y Maeterlink, al constituir ambos en sus respectivas tierras la dramaturgia "oficial", reconocida y valorada como tal nacionalmente e internacionalmente, en contra de los iconoclastas rezagados. Valle-Inclán, gallego hasta en la médula, siempre hace sus reflexiones más allá del costumbrismo y el constructivismo localista, para situarse en un plano europeo, ("España es una deformación grotesca de la civilización europea") y mundial ("El mundo es un esperpento"), para citar solo dos clásicos ex-abruptos de Max Estrella, su portavoz.

Para Valle-Inclán prevalece entonces siempre cierta voluntad de enseñar, muy paternal y decimonónico en Romance de Lobos, directo y subversivo en sus últimas creaciones. También le da lo mismo partir de la realidad, como en La hija del capitán, reflexión feroz sobre su entorno inmediato, como partir del arte, como en Las galas del difunto, donde recrea el mito de Don Juan. La realidad tangible en un caso, la visión cultural en otra, siempre con una perspectiva renovadora de parte de Don Ramón.

En el contexto de la funcionalidad del teatro, según Valle-Inclán, es interesante también volver a descubrirlo, a estas alturas finiseculares, como exponente destacado de una visión antimilitarista que estaba presente en el ambiente de su época (con figuras europeas como Leon Tolstoi, Romain Rolland y otros), para dar al respecto la dimensión española: tanto Los cuernos de Don Friolera como La hija del capitán son dos exponentes de teatro eminentemente desmitificador respecto de lo militar y lo nacional: la "charanga y pandereta" machadiana tienen aquí su refuerzo teatral. Eminentemente local y adscrito a un momento de la historia española (Valle habría podido exclamar, igual que Unamuno, que "le dolía España"), este mismo teatro 
adquire también una tremenda fuerza en otras latitudes y momentos, al ver la actualidad que puede tener este tipo de teatro, por ejemplo en el contexto americano de una Costa Rica y Panamá, legalmente sin ejercitos, y en Haití, un general Cedras patriotero y fantoche. Frente a los apologistas de la seguridad nacional de los años setenta, especialmente en Brasil y en el Cono sur, el teatro de Don Ramón, a medio siglo de distancia, ya ofrecía lo que por ejemplo Luis Puenzo daría, en lo fílmico, con su subversiva Historia Oficial, que como se sabe, ya desde el mismo título aduce corrosivamente que lo oficial, en este caso, no resulta sino toda una deformación.

\section{Valle-Inclán, precursor también en la búsqueda formal}

En varios momentos anteriores se ha visualizado un afán de renovación de nuestro artista, también en la forma. "Ya llegará nuestra hora" es otra frase de su anecdotario que parece encontrar su asidero en múltiples elementos de renovación. La cantidad de acotaciones, el planteamiento de situaciones solo sobre el papel, sin posibilidad de concreción por mucho tiempo o para siempre, son característicos en este sentido. Es sintomático, al respecto, que los dramaturgos de la época republicana, en los años treinta, si bien tenían una gran admiración por Don Ramón y si bien explotaron su nombre y su obra para su molino ideológico ${ }^{21}$, respecto del dramaturgo, como artista, y como acertadamente lo postula Buero Vallejo ${ }^{22}$, no manifestaban tampoco o todavía una adecuada comprensión. Prueba está en que ninguna sigue la huella investigativa planteada por el genial gallego, en lo formal. No hay en el teatro republicano de Lorca, de Casona, de Aub y otros rastro palpable de esperpento o de búsqueda formal como la que obsesionaba a Valle-Inclán. El teatro de "La Barraca" y de las "Misiones Pedagógicas" era un teatro quizá revolucionario por sus propulsores y por lo avanzado de sus objetivos de divulgación, pero no por su búsqueda formal. El concepto de "lo popular" que ellos manejan en sus obras, reanuda con el populismo del Siglo de Oro, pero no tiene el germen de lucha de clases que sí encontramos en Romance de lobos, por ejemplo.

En cambio a estas alturas, solo que en otra latitud europea, esta vez en la Alemania nazi, un creador e investigador, aparentemente sin ninguna relación de conocimiento con Valle-Inclán, retoma la bandera e incluso la lleva más lejos: vale la pena preguntarse en qué grado el concepto de teatro postulado por Don Ramón, con su necesaria artificialidad, no la copia de la realidad (punto 3 ) y el concepto de funcionalidad y por ende de público postulados (punto 4) no presuponen ya el germen del distanciamiento brechtiano ${ }^{23}$.

Valle-Inclán es precursor del alemán por su búsqueda de instrumentos adecuados para llevar a cabo en el público la auténtica función catalizadora en que consiste el teatro. Ambos se proponen obtener el mismo resultado de participación aumentada en el espectador. El distanciamiento requerido por el alemán y la sátira esperpéntica postulada por el español son de una misma índole al buscar producir en el receptor una ruptura, una actitud crítica respecto de lo que ve y lo que debe ver o pensar. Es posible ahondar bastante en la comparación entre los dos autores, más allá del desfase cronológico que los separa, nuevamente con Valle anterior a Brecht, en un plano de reacción a un mismo generador: el contexto europeo de las primeras décadas ${ }^{24}$. En aras de la comparación y el parecido entre los dos, Buero Vallejo destaca también como felizmente los dos no fueron fieles a la letra de su teoría para dejar alma, humanidad, en sus creaciones, más allá de los modelos teóricos y un heroísmo acartonado ${ }^{25}$. 
Hay, sin embargo, sustanciales diferencias también, entre los dos. El distanciamiento brechtiano resulta doble, primero en el plano de la relación escenario-público, en seguida, y en forma complementaria, en el plano de la actuación, con la "Verfremdung" interna entre el actor y su actuación. Pareciera que no se pueden descubrir rastros de esto último ni en la escasísima reflexión teórica de Valle, ni en su misma producción artística teatral. Su concepción autoritaria del dramaturgo no permite postular una teoría del actor.

\section{El desfase político}

Del mismo Ruibal citado es también la expresión según la cual "El dramaturgo es una conciencia. Por eso molesta" ${ }^{\prime 2}$. El caso de Valle-Inclán es evidente en este sentido. Resulta entonces que aparte del genial talento precursor que lo caracteriza en lo estético (puntos 3, 4 y 5), un factor eminentemente político condena al autor a una demora adicional de dos décadas. De no ser por el el bloqueo fascista que se impuso en España a partir de 1939, Valle-Inclán habría podido ser apreciado ya en los años cuarenta y cincuenta, como contemporáneo espiritual de Brecht. Las circunstancias lo decidieron de otro modo: en estas décadas la sociedad española, por lo menos en ojos de los vencedores en el conflicto fratricida, no se podía permitir la interrogación artística, lo corrosivo de un Valle-Inclán. Es que releyendo a Don Ramón, por ejemplo en la proclama de Don Juan Manuel Montenegro en Romance de Lobos ("Tenéis marcado el hierro de los esclavos (...). El día en que los pobres se juntasen para quemar las siembras (...) sería el día de la gran justicia... Este día llegará"), uno encuentra un dramaturgo que, lejos del patriarcalismo religioso inicial, ha evolucionado hacia términos de socialismo anticlerical. La España de Franco quería jugar con valores seguros. Surge entonces toda una manipulación orquestada del gusto artístico.

Como quedó investigado ${ }^{27}$, junto con un "recalentamiento" programado de autores à la Benavente, asistimos en estos años al estímulo sistemático de un teatro seudo-político como refuerzo de la ideología dominante: es el caso de Calvo Sotela, Mihura y tantos otros, incluyendo en los años sesenta ya la reincorporación adormecedora de Casona, temprano en los años sesenta, directamente en teatro comercial. En este contexto no cabía un Valle-Inclán. Lo mismo ya le había pasado a Don Ramón, en vida: la dictadura de Primo de Rivera no se limitó a prohibir la producción del gallego sino que finalmente también lo encarceló. Después del breve interregnum de la época de la República, el sistema franquista tampoco permitió la rebeldía antimilitarista, antipatriotera (¡que no antipatriota!) e inconformista de Valle-Inclán.

Frente a estos "martes" (plural de 'hombres dedicados al arte de la guerra') a ValleInclán no le queda otra que sobrevivir artisticamente por medio de la literatura dramática: así lo hizo, en vida, a fines de los años veinte, precisamente con Martes de Carnaval, agrupación de tres textos clásicos del esperpento. Después, a partir de los años cincuenta pasa lo mismo, con la publicación de ciertas de sus obras. Hay que esperar los años sesenta para un progresivo rescate estético y un relativo deshielo político. En lo teatral, por medio de la censura, entre otros el control sobre el teatro de cámara ${ }^{28}$ hay un manejo como válvula de escape. En 1957 se estrena Ligazón y Melodrama para marionetas, así como La marquesa Rosalinda; hay una versión de cámara de Don Friolera en 1958; Divinas palabras vuelve a ver la luz pública en 1962 29 ; Águila de Blasón en 1966; La cabeza del bautista, La enamorada 
del rey y La rosa de papel, en 1967; Cara de plata en 1968, en teatro de cámara. Luces de bohemia tiene que esperar su turno en teatro comercial hasta 1971. Habría que ahondar, además, en qué tipo de versión se permitió, necesariamente mutilada en aras de la conceptualización estética y política del régimen.

Respecto de Costa Rica, Valle-Inclán tuvo que esperar otra década más, totalizando medio siglo de desfase. En 1977 el Teatro del Angel estrena con buen éxito Los cuernos de Don Friolera. En 1978, gracias a la gira del Teatro María Guerrero de España, se dan a conocer otros dos esperpentos: Las galas del difunto y La hija del capitán. Para explicar este singular desfase prevalecen todas las razones analizadas anteriormente, excepto naturalmente la política, circunscrita a la España. Pero se añade otra, en sustitución, cual es la existencia de una cultura periférica. Finalmente, para bien de la cultura universal, ha llegado la hora de Valle-Inclán.

\section{Notas}

1. Ruiz Ramón, Francisco: Historia del teatro español, Ed. Cátedra, Madrid, 1975, título del capítulo III.

2. Este artículo arranca en una contribución académica del ponente ("Valle-Inclán en las disyuntivas del teatro contemporáneo", publicada en La Estafeta Literaria, Madrid, agosto 1971, p. 4-8), pero radicalmente transformada y actualizada en función de un seminario ("La modernidad en el mundo iberoamericano: Valle-Inclán”), celebrado en San José, Costa Rica, en setiembre 1994 en los locales del Instituto de Cooperación Iberoamericana.

3. Buero Vallejo, Antonio: "De rodillas, en pie, en el aire", en Revista de Occidente, Madrid, IV, 1966, p. 132-145.

4. No deja de ser curioso observar, por de pronto que Buero Vallejo, autor de auténticas obras trágicas, (por eso la citación de este título suyo), a pesar de estar entre los más agudos teóricos sobre el dramaturgo Valle-inclán y lo trágico de su visión esperpéntica, en la práctica de su creación teatral nunca refleja huella directa del gran gallego, sino que se mantiene dentro de los cánones aristotélicos: esta paradoja habría de ser investigada más a fondo.

5. En realidad, por la bibliografía consultada, no está claro cuáles de sus obras fueron realmente estrenadas. Para la mayoría, Valle sufrió el ostracismo del público. He aquí la cronología de las principales obras teatrales de Valle-Inclán, en las que se apoyará ese ensayo sobre el carácter precursor de su autor: Romance de lobos data de 1907; Divinas Palabras y Luces de Bohemia de 1920; Los cuernos de Don Friolera es de 1921; Las galas del difunto de 1926 y La hija del capitán de 1927.

6. Es el texto ya clásico ahora por su rescate y estudio en el artículo de Buero Vallejo, citado.

7. En la discusión que siguió a esta ponencia, en el seminario ya mencionado, alguien señaló que Valle-Inclán habría declarado alguna vez que su estadía en México - precisamente durante los años de la tremenda efervescencia revolucionaria - le había cambiado totalmente su modo de ver.

8. Partiendo de la definición de "moderno" dada por Alexander Jiménez ("En el imaginario occidental moderno es lo nuevo que se impone de moda y como norma. (...) Los hombres modernos se orientan hacia el futuro ..." (Rumbo, San José, Costa Rica, 23 de agosto de 1994, p. 44), Valle-Inclán es "moderno" por antonomasia.

9. Guerrero Zamora, en su clásica Historia del Teatro contemporáneo, Flors Editor, Barcelona, 1961, p. 154, a mi modo de ver cae en este error, a pesar de negarlo. 
10. Allí está el conocido grito-postulado de Max Estrella en Luces de Bohemia: "El sentido trágico de la vida española sólo se puede dar con una estética sistemáticamente deformada. (...) La deformación deja de serlo cuando está sujeta a una matemática perfecta".

11. Esta insistencia en lo feo, predilección por lo feo, podríamos decir, se visualiza más al pensar en el mismo término de "esperpento" que, específicamente en francés por ejemplo, equivale con espantapájaros, con la imagen de los brazos en aspavientos, algo necesariamente exagerado y feo, cuyo propósito es precisamente asustar.

12. Hay que recordar que recién en 1932 Antoine Artaud publica su clásico Le théâtre de la cruauté.

13. Ver, al respecto un artículo mío, escrito junto con dos colegas: "Aproximación semiótica a 'Los cuernos de Don Friolera', en Káñina, Universidad de Costa Rica, II, nº 3-4, julio-diciembre 1977, pp. 85-97.

14. Obra citada, p. 131.

15. Recordemos que según el mismo Valle, la manera "de rodillas" corresponde al modelo de Homero; la manera "en pie" se visualiza en Shakespeare y la tercera, con la que se identifica el autor, es "una manera muy española”, practicada también por Quevedo, Cervantes y Goya, como precursores. (Ver el artículo de Martínez Sierra, citado anteriormente).

16. Es la línea del didactismo simplificador, como en la Historia de la Litratura Española de García López, ed. Vicens Vives, Barcelona, 1972.

17. No tengo conocimiento de alguien que haya invesigado a fondo este paralelo, desde una óptica europea.

18. Ver también en el punto 3, anterior: así las cosas, ya se visualiza el acercamiento de ambos con Brecht: entre la distancia evocada, y la técnica "sistemática" (otra vez Max Estrella) del distanciamiento, solo hay un paso. El mismo Brecht postulaba ya la radical interferencia entre fondo y forma: "la forma es la estructura del fondo".

19. Ver nota 11, en cuanto al significado del término "esperpento".

20. En horor a la verdad, justo es señalar también que cada vez media casi una generación entre estos oponentes: en todo caso, la comparación ilustra el carácter de incomprendidos, por precursoses, tanto de Valle-Inclán como de Ghelderode.

21. En 1933, por ejemplo, se registra una escenificación de Divinas Palabras en el Teatro Español, de Madrid, con Margarita Xirgú como Mari Gaila.

22. Ver su artículo citado.

23. Es más lógico hablar de distanciamiento, con el término brechtiano aplicado al esperpento de Valle- Inclán, que al revés, como por cierto hace Alfonso Sastre (Anatomía del realismo, Barcelona, Seix-Barral, pp. 5667), al referirse al "esperpento constructivo" de Brecht. Al añadir un adjetivo, para indicar un tipo de tono general en Brecht (en contra de lo "destructivo", se supone, en Valle-Inclán), se desvía la atención hacia aspectos de tono, cuando en realidad se trata de una comparación en cuanto a formas, o métodos de construccion artística. En Valle y Brecht hay una similar técnica de distanciamiento, que -eso si- Valle utiliza especialmente en la distancia y deformación de lo feo, como lo sugiere el nombre mismo de su técnica: ver también nota 11 .

24. El mismo Alfonso Sastre de la nota anterior señala al respecto: "Basta con mirar el panorama literario europeo de los últimos sesenta años para comprobar que lo español no posee la exclusividad del esperpento".

25. En el mismo artículo citado.

26. Expresión que le he oido personalmente en 1971. 
27. Mi tesis de doctorado ("Condicionantes para el dramaturgo y su obra en el Madrid de posguerra"), con cuatro volumenes sin publicar, presentada en la Universidad Complutense de Madrid en 1977, se refiere en forma extensa a la problemática de la postergación, manipulación y recuperación de ciertos autores, entre otros Valle-Inclán, en función del contexto evolutivo del régimen franquista.

28. Para un seguimiento de la presencia de Valle-Inclán, específicamente en Madrid, en el teatro de cámara, ver también mi tesis, mencionada en la nota anterior. Ver además el artículo mío "El teatro de cámara en la posguerra española (su importancia, su fuerza, su debilidad)", en la revista Segismundo, C.S.I.C., Madrid, XII, nº 1-2, 1976, pp. 173-179.

29. Desde 1962 existe también en Madrid un Teatro Valle-Inclán. Esta salida del autor del ostracismo oficial, por lo menos a nivel de nomenclatura, puede perfectamente conllevar su grado de hipocresía y no augura necesariamente una comprensión o aceptación del dramaturgo y de sus ideas o de su estética por parte de los sectores entonces dominantes.

\section{Bibliografía}

Buero Vallejo, Antonio: 1966. "De rodillas, en pie, en el aire". Revista de Occidente. 4: 132145 .

Guerrero Zamora. 1961. Historia del Teatro contemporáneo. Barcelona: Flors Editor.

Ruiz Ramón, Francisco . 1975. Historia del teatro español. Madrid: Editorial Cátedra,

Sastre, Alfonso. Anatomía del realismo. Barcelona: Seix-Barral. 56-67.

Valembois, Víctor: 1971. "Valle-Inclán en las disyuntivas del teatro contemporáneo". La Estafeta Literaria. 4-8.

Valembois, Víctor (en colaboración) .1977. "Aproximación semiótica a Los cuernos de Don Friolera. Káñina. 2 (3) (4): 85-97.

Valembois, Víctor. 1977.Condicionantes para el dramaturgo y su obra en el Madrid de posguerra. Tesis doctoral: Universidad Complutense de Madrid.

Valemboís, Víctor. 1976. "El teatro de cámara en la posguerra española (su importancia, su fuerza, su debilidad)". Segismundo. C.S.I.C., 12 (1) (2): 173-179. 